\title{
Using Linear Spectral Method when Calculating Seismic Resistance of Large-Capacity Vertical Steel Tanks
}

\author{
Alexandr Tarasenko ${ }^{1}$, Petr Chepur ${ }^{1, *}$, and Alesya Gruchenkova ${ }^{1}$ \\ ${ }^{1}$ Industrial University of Tyumen, 625001 Volodarskogo str. 38, Tyumen, Russia
}

\begin{abstract}
The paper is aimed at determining the possibility of applying the simplified method proposed by the authors to calculate the tank seismic resistance in compliance with current regulations and scientific provisions. The authors propose a highly detailed numerical model for a common oil storage tank RVSPK-50000 that enables static operational loads and dynamic action of earthquakes to be calculated. Within the modal analysis the natural oscillation frequencies in the range of $0-10 \mathrm{~Hz}$ were calculated; the results are given for the first ten modes. The model takes into account the effect of impulsive and convective components of hydrodynamic pressure during earthquakes. Within the spectral analysis by generalized response spectra was calculated a general stress-strain state of a structure during earthquakes of 7, 8, 9 intensity degrees on the MSK-64 scale for a completely filled up, a half-filled up to the mark of $8.5 \mathrm{~m}$ and an empty RVSPK-50000 tank. The developed finite element model can be used to perform calculations of seismic resistance by the direct dynamic method, which will give further consideration to the impact of individual structures (floating roof, support posts, adjoined elements of added stiffness) on the general stress-strain state of a tank.
\end{abstract}

\section{Introduction}

Development of the main oil transport facilities infrastructure and emergence of new supply routes leads to the need for construction of commercial oil and oil products depots in areas with high seismic activity. According to the OSR-97-S maps of seismic zoning of Russia practically all regions of the Far East, Altai, Transbaikal have a 5\% likelihood of an increase in earthquakes of 7 degrees intensity on the MSK-64 scale. In the North Caucasus in such conditions large-capacity oil depots are exploited including vertical steel tanks of up to $100,000 \mathrm{~m} 3$. To ensure safe operation of large tanks, failure of which may result in environmental and material damage [1-5], it is necessary to develop and improve approaches to calculation of seismic resistance of such facilities.

Currently, there are 3 main methods of calculating structures for seismic effects: static, linear spectral and direct dynamic. The most simple method - static - is based on the assumption that the structure moves with the subgrade in a horizontal plane by a certain law $\mathrm{y} 0(\mathrm{t})$ without undergoing rotational movements. This method is of little use if you want to

*Corresponding author: chepur@me.com 
calculate the seismic resistance of tanks, because it does not take into account features of the hydrodynamic fluid impact on the wall, the base and structures ductility, etc.

Direct dynamic method allows for a highly precise estimation of the vertical steel tank (VST) design stiffness based on the stored liquid, which makes it more attractive for solving specific engineering problems. If there are calculated accelerograms, representing a three-component function of acceleration to time, it is possible to determine deformation, strain and displacement in all points of the structure and fluids for a particular construction site at any moment of time t. Often, however, the results of microseismic zoning of the site are not available, forcing to "pick out" the most suitable existing design accelerograms. For example, in [3] using the direct dynamic method were obtained design calculations of the earthquake impact on the stress-strain state (SSS) of an insulated LNG storage tank, and was proposed a method of reducing the frequency of natural oscillations of the tank by applying damping inserts. However, the results can be extended only on tanks built according to the Chinese project for a specific site with a given impact accelerogram. Experimental studies on seismic action on tanks using reduced models - "vibrating platetank-liquid" systems are presented in $[1,3]$. These experiments made it possible to obtain high-quality results aimed at further optimizing the design numerical models. Direct dynamic method involves considerable machine time costs (supercomputers of special configuration are required) and complexity of results processing. We propose to use the main provisions of the linear spectral theory of calculating the seismic action for a common in Russia large-sized tank RVSPK-50000. According to this approach, seismic action is considered as a spectrum - dependence of acceleration on frequency. The calculation includes calculating the participation factor of each oscillation mode with the natural frequency of the tank structure, determining the maximum acceleration response, inertial forces and displacements for each mode of the predetermined response spectrum in the initial system. In practice, the main advantage of this method is that the response spectrum can be obtained by synthesizing the accelerograms of real earthquakes. At the same time, the more of them have been taken into account in constructing the action spectrum, the less likely it is that the loading on the tank will exceed the anticipated when the new earthquake occurs.

\section{Design scheme}

To analyze seismic resistance of the RVSPK-50000 tank, designed by "CNIIPROEKTSTALKONSTRUKCIYA" $(\mathrm{D}=60.7 \mathrm{~m}, \mathrm{H}=17.95 \mathrm{~m})$ the authors carried out a modal analysis to determine the natural frequencies and modes of the structure oscillations. For static problems, the geometric tank model has been developed and verified by the authors in [6-15] using the ANSYS software package, then its optimization was conducted and it was exported to modules «Modal» and «Response Spectrum» to solve dynamic problems.

Let us look at the basic steps of a modal analysis of RVSPK-50000.

- The model has set material properties: 09G2S tank steel with a yield point $\sigma_{\mathrm{T}}=325$ $\mathrm{MPa}, 16 \mathrm{G} 2 \mathrm{AF}$ steel with a yield point $\sigma_{\mathrm{T}}=410 \mathrm{MPa}$ and oil with a density of 865 $\mathrm{kg} / \mathrm{m}^{3}$; metal structures are modeled by finite elements SHELL181, BEAM188, SOLID186, oil stored in the tank is modeled by tetrahedral elements FLUID80;

- The calculation is performed for the three cases of VST fill-up: emptied, filled up halfway $\left(\mathrm{H}_{\text {взл }}=8.5 \mathrm{~m}\right)$ and filled up to the top level $\left(\mathrm{H}_{\text {взл }}=17 \mathrm{~m}\right)$;

- The boundary conditions allow for rigid mounting of the foundation ring, unbroken contact of the bottom and wall with the foundation and the possibility of separation of the central part of the bottom from the subgrade, the properties of which are specified by the coefficient of subgrade reaction $\mathrm{k}=200 \mathrm{MN} / \mathrm{m}^{3}$ (for compacted sand); 
- The contact of the walls and bottom with the liquid is determined by the function «no separation», which allows one to simulate the fluid sliding along the wall and bottom during oscillations.

According to [16-19], the results obtained by the modal analysis of RVSPK-50000 and further test calculations, most devastating effects are observed at the oscillation frequency from 0 to $10 \mathrm{~Hz}$. At such frequency the greatest contribution is made by impulsive (inertial) and convective (kinematic) components of hydrodynamic pressure, so the most unfavorable case is the design scheme with a completely filled up oil tank. Figure 1 provides the results of calculating the natural oscillation frequencies of RVSPK-50000 completely filled up to the design level. 10 modes were determined in the calculation; the figure shows general deformations diagrams of the first 6 modes and with the frequency not exceeding $10 \mathrm{~Hz}$.

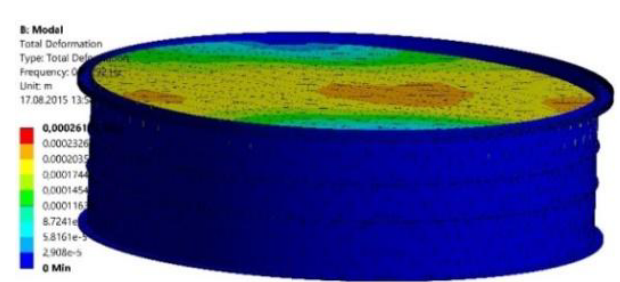

1st oscillation mode,

natural frequency $\mathrm{f}=0.33 \mathrm{~Hz}$

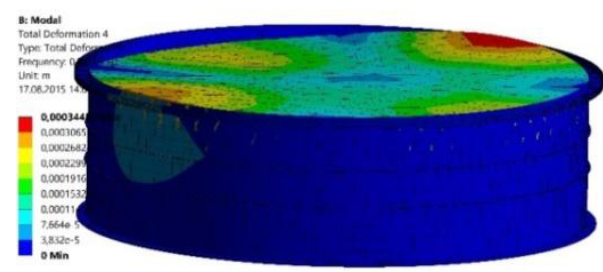

4th oscillation mode,

natural frequency $\mathrm{f}=0.94 \mathrm{~Hz}$

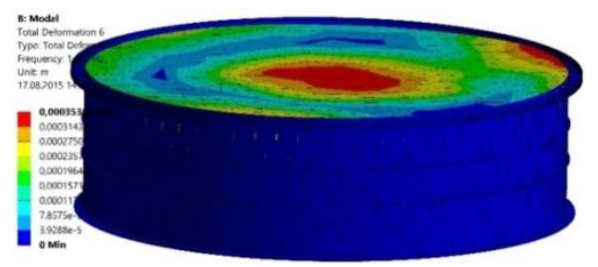

6th oscillation mode,

natural frequency $\mathrm{f}=1.19 \mathrm{~Hz}$

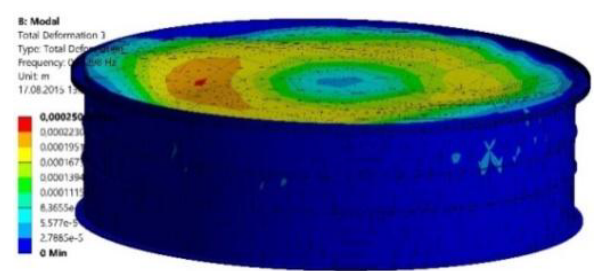

3rd oscillation mode,

natural frequency $\mathrm{f}=0.54 \mathrm{~Hz}$

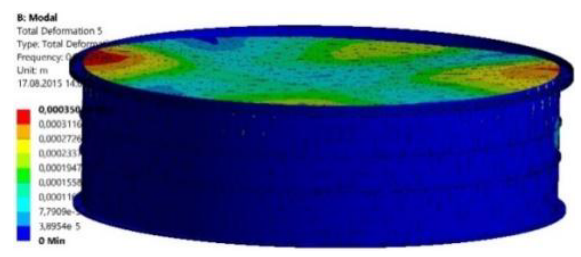

5th oscillation mode,

natural frequency $\mathrm{f}=0.97 \mathrm{~Hz}$

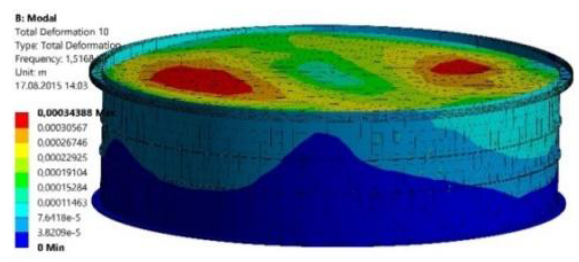

10th oscillation mode,

natural frequency $\mathrm{f}=1.52 \mathrm{~Hz}$

Fig. 1. Determining the natural oscillation frequencies of RVSPK-50000, completely filled up to the mark of Нвзл $=17 \mathrm{~m}$.

Table 1 provides the results of calculating the natural oscillation frequencies for the three cases of RVSPK-50000 fill-up at 10 oscillation modes. 
Table 1. Results of calculating the natural oscillation frequencies of RVSPK-50000.

\begin{tabular}{|c|c|c|c|c|c|c|c|c|c|c|}
\hline $\begin{array}{c}\text { RVSP } \\
\text { K- }\end{array}$ & \multicolumn{10}{|c|}{ № of oscillation mode } \\
\hline fill-up & & & & & & & & & & \\
\hline $\begin{array}{l}\text { Natural } \\
\text { oscillati } \\
\text { on } \\
\text { frequen } \\
\text { cy, } \mathrm{Hz}\end{array}$ & I & II & III & IV & V & VI & VII & VIII & IX & $\mathrm{X}$ \\
\hline $\begin{array}{c}\text { Emptie } \\
\mathrm{d} \text { tank }\end{array}$ & $\begin{array}{c}10.0 \\
4\end{array}$ & 10.05 & 10.1 & 10.16 & 10.24 & 10.25 & 10.26 & $\begin{array}{c}10.2 \\
7\end{array}$ & $\begin{array}{c}10.2 \\
7\end{array}$ & $\begin{array}{l}10 . \\
28\end{array}$ \\
\hline $\begin{array}{c}\text { Filled } \\
\text { halfwa } \\
\mathrm{y} \\
\text { Нвзл=7 } \\
.5 \mathrm{~m} \\
\end{array}$ & 0.27 & 0.28 & 0.25 & 0.84 & 0.92 & 1.13 & 1.22 & 1.28 & 1.46 & $\begin{array}{c}1.5 \\
4\end{array}$ \\
\hline $\begin{array}{c}\text { Comple } \\
\text { tely } \\
\text { filled } \\
\text { Нвзл=1 } \\
7 \mathrm{~m} \\
\end{array}$ & 0.33 & 0.34 & 0.54 & 0.95 & 0.97 & 1.19 & 1.26 & 1.31 & 1.42 & $\begin{array}{c}1.5 \\
2\end{array}$ \\
\hline
\end{tabular}

To perform linear spectral analysis of seismic action the addition of responses calculated from the obtained values of natural modes and oscillation frequencies of the structure was carried out. The SRSS (Square Root of Sum of Squares) method of modes combination was used enabling the input of each oscillation mode in the overall system to be summarized. According to [19], this method yields reliable estimates, if the natural frequencies differ greatly from each other (in our case, the frequencies range from 0.2 to 30 $\mathrm{Hz})$.

To set the external seismic action we used generalized broadband seismic response spectra digitized in [20]. For obtaining acceleration components a formula was used that takes into account the impulse duration, start time and end time, as well as the amplitude:

$$
a(t+\tau)=a_{m} \sin \left(\frac{\pi \tau}{L}\right)
$$

where $L$ - the impulse duration; $t$ - the impulse start time; $\tau$ - the time within the impulse, $0 \leq \tau \leq L ; a_{m}-$ the impulse amplitude.

In Russian design practice it is conventionally recommended to use only one synthesized accelerogram SA-482, established in [18] and underlying the seismic response spectra in this paper. When calculating the structures for seismic resistance within the linear spectral method as a mathematical model of the seismic action a response spectrum is used. It is a graph of the maximum acceleration $\mathrm{A}(\omega)=\max (\ddot{\mathrm{x}}(\mathrm{t}))$ dependence of the oscillators on their natural frequency $\omega_{\mathrm{m}}$ at a given value of the oscillation attenuation $\delta_{\mathrm{d}}$ due to the action of the accelerograms a(t) (real, synthesized or probabilistic and statistical). 


\section{Results}

Fig. 2 shows the horizontal and vertical ground accelerations dependences on the wave frequency in the range from 0 to $30 \mathrm{~Hz}$ used when calculating the seismic action on RVSPK-50000 by the spectral method for earthquakes of 7, 8, 9 intensity degrees on the MSK-64 scale. For areas with the seismic activity of 6 degrees and below the seismic loads are not required to be considered [22]. The logarithmic decrement is assumed to be $\delta_{\mathrm{z}}=$ 0.31 for a steel welded structure. The vertical acceleration component value is reduced by a factor of 0.67 from the values of the horizontal components $\mathrm{X}$ and $\mathrm{Y}$, in accordance with [17].

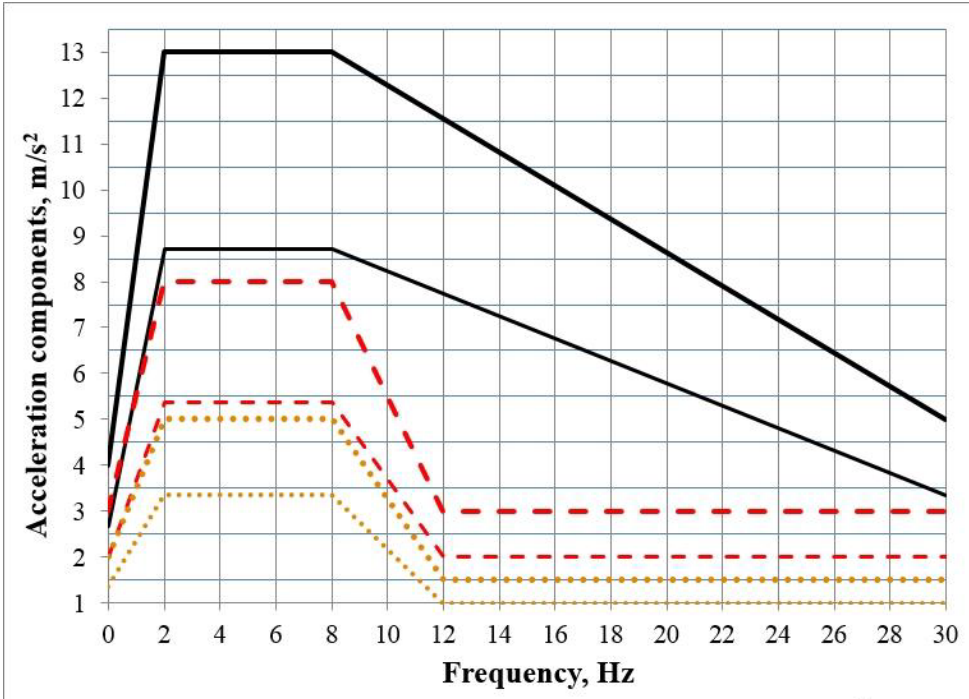

Horizontal components X, Y

Horizontal components $\mathrm{Z}$

9 degrees on MSK-64

- 9 degrees on MSK-64

- -8 degrees on MSK-64

- -8 degrees on MSK-64

$\ldots 7$ degrees on MSK-64

7 degrees on MSK-64

Fig. 2. Seismic response spectra for earthquakes of 7, 8, 9 intensity degrees on the MSK-64. Scale.

A design scheme of the RVSPK-50000 tank filled to the top mark and located on the elastic Winkler base is given in Fig. 3.

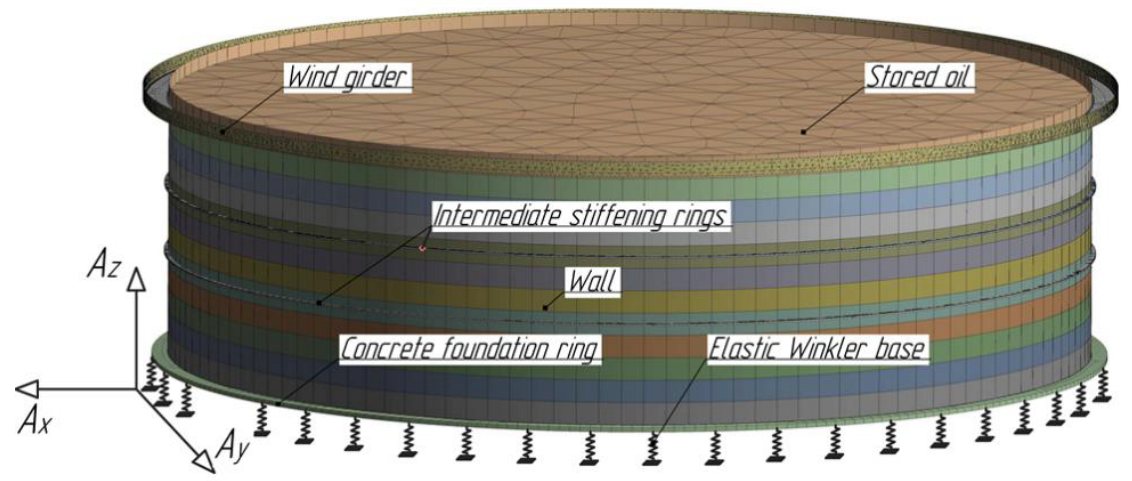

Fig. 3. Design scheme for spectral analysis of RVSPK-50000.Ax, Ay, Az - components of the horizontal and vertical accelerations under the seismic action. 


\section{TPACEE-2016}

The results of the numerical calculation carried out in the ANSYS «Response Spectrum» software module show that the case when the tank is completely filled up is the most dangerous. A 9-degree seismic action on the MSK-64 scale (substantial destruction of moderate severity, according to the classification) results in considerable hydrodynamic loads, impulsive and convective components of the stored oil cause the appearance of unallowable stresses in the wall that exceed the 09G2S tank steel yield point $\sigma_{\mathrm{T}}=325 \mathrm{MPa}$ for the top wall belts in a neutral layer (Fig. 4), with stresses greater than $400 \mathrm{MPa}$ arising in the outer shell layer of the first belt.

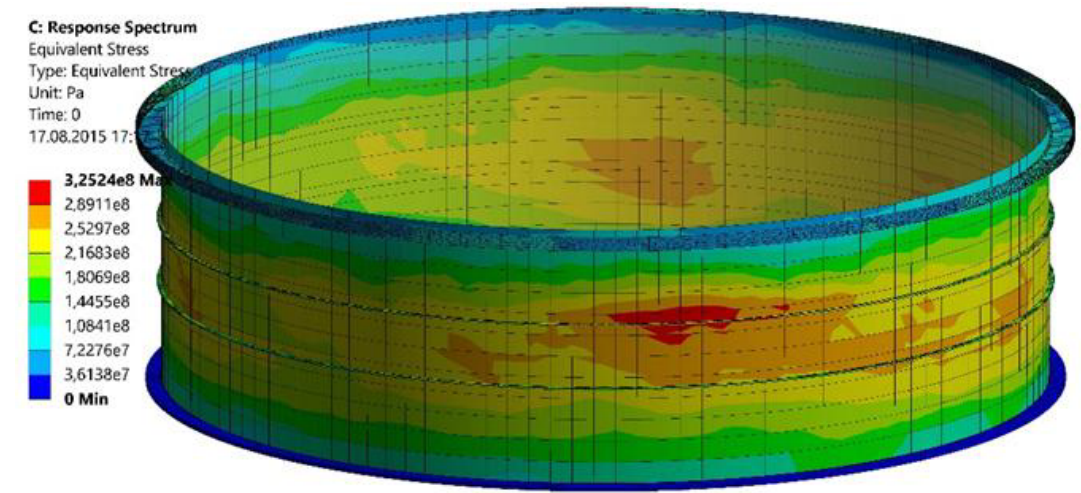

Fig. 4. Distribution of equivalent stresses in RVSPK-50000 structures (neutral layer) at a 9-degree earthquake intensity on the MSK-64 scale.

Reduction in the seismic action intensity and the volume of stored oil decreases the SSS level of the shell. So, in an empty tank the acting equivalent stresses in various metal structures do not exceed $10 \mathrm{MPa}$ at a 9-degree earthquake intensity. The authors have produced a graph (Fig. 5) built on the results of spectral analysis which reflects the dependences of the structure SSS level on the value of the product filling during earthquakes of 7, 8, 9 intensity degrees.

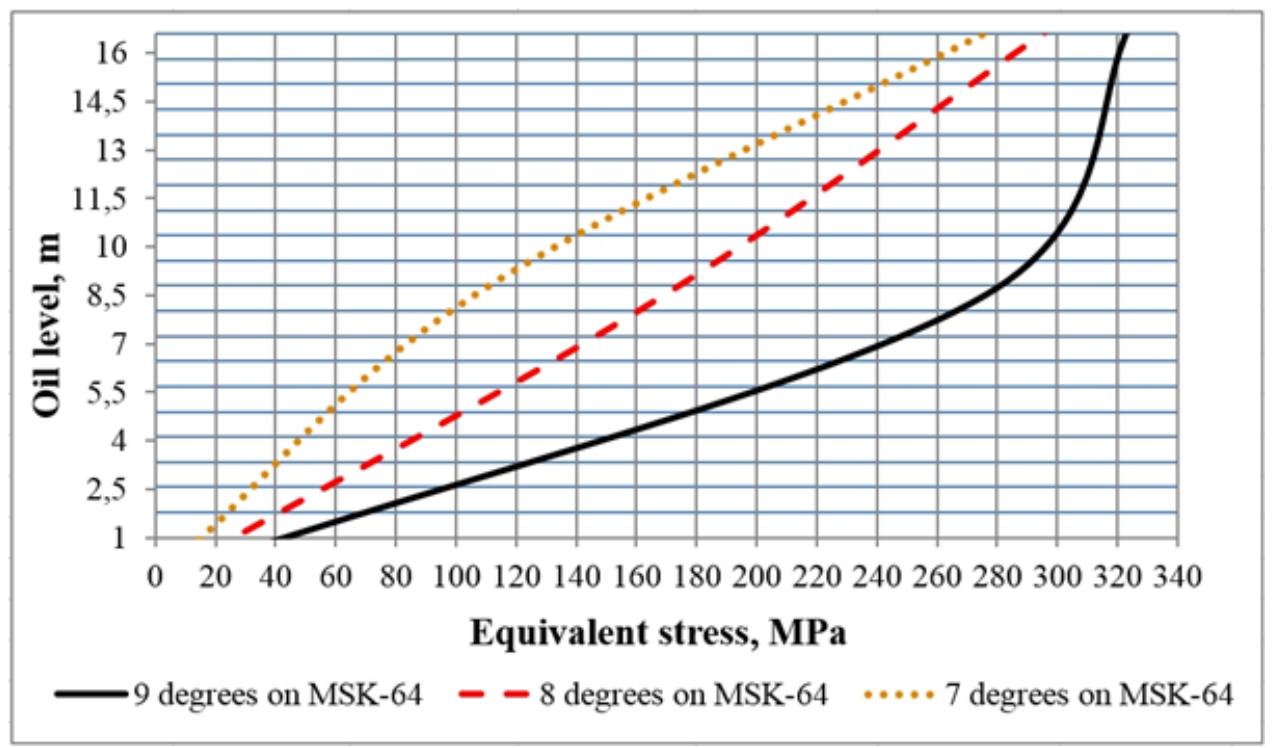

Fig. 5. Dependencies of acting stresses in the neutral wall layer of RVSPK-50000 under seismic actions of 7, 8, 9 intensity degrees. 
A high-detail model (the edge length of individual elements is $5 \mathrm{~mm}$ ), consideration of design geometry and material properties of the tank built on a real project allowed us to obtain the results of the RVSPK-50000 metal structures SSS under seismic actions with an accuracy unattainable by conventional methods.

Linear spectral method with the implementation in the finite element software package actually is a static calculation taking into account seismic forces in the same manner as other static loads. At the same time, it takes into account dynamic characteristics of the calculated structure - natural frequencies, modes and attenuation parameters. When calculating the seismic impact on the oil tank, an advantage of the method is the ability to take into account only a limited number of lower system natural modes caused by the fluid vibration. However, linear spectral method has certain limitations that do not allow taking into account the behavior of the structure during separation (both in case of fixing by anchors, and free support).

\section{Conclusions}

Analyzing the calculation results, the authors concluded that earthquakes with a large magnitude put at most risk tanks that are completely filled up with product. Thus, it is necessary to develop technological schemes according to which an early warning of a possible earthquake would be possible to redistribute the volume of the stored liquid throughout the tank farm so that each tank would have the lowest level possible [20-22]. This will significantly reduce the probability of failure and structural damage during a possible earthquake. In 2013, for example, after a powerful earthquake in the Chinese province of Sichuan, it was decided to invest more than $\$ 300$ million in the forecast of seismic shocks: in the most dangerous areas of the country a network of 5,000 observation stations will be set up, the purpose of which is an early warning of severe earthquakes.

A separate issue, which until now has not been fully investigated, is analysis of the influence of the floating roof and pontoon on the tank SSS under seismic actions. Consideration of the contact interaction of the "liquid-pontoon-wall" system is complicated by the fact that a precise modeling of the hydraulic seal, support posts and other structures can solve only a narrow engineering problem for a specific project, without obtaining a generalized solution suitable for amending the existing regulatory and technical documentation. The approach proposed by the authors allows the level of seismic load effect on a tank to be reduced by selecting the damping devices installed between the base and metalwork of the structure.

\section{References}

1. G.G. Vasilyev, A.A. Tarasenko, P.V. Chepur, Y. Neftyanoe khozyaystvo, Oil Industry, 10, 120-123 (2015)

2. A.S. Gorelov, Inhomogeneous ground base and their influence on the operation of vertical steel tanks: monograph (Nedra, SPb, 2009)

3. M. De Angelis, R. Giannini, F. Paolacci, Experimental investigation on the seismic response of a steel liquid storage tank equipped with floating roof by shaking table tests, EarthquakeEngngStruct Dyn. 2009. DOI: 10.1002.

4. P.A. Konovalov, R.A. Mangushev. S.N. Sotnikov, A.A. Zemlyanskiy, A.A. Tarasenko, Foundations of steel tanks and deformations of their bases (Publishing house Associacii stroitel'nyh vuzov, Moscow, 2009)

5. A.A. Tarasenko, Development of scientific principles of vertical steel tanks repairs methods. Thesis for the degree of Doctor of Technical Sciences (Tyumen State Oil and Gas University, Tyumen, 1999) 
6. A.A. Tarasenko, A.A. Gruchenkova, P.V. Chepur, Pipeline transport: Theory and Practice, 53, 32-37 (2016)

7. A.A. Tarasenko, P.V. Chepur, A.A. Gruchenkova, Fundamental research, 12-7, 1418 $1422(2014)$

8. A.A. Tarasenko, P.V. Chepur, D.A. Tarasenko, Neftyanoe khozyaystvo, Oil Industry, 4, 88-91 (2015)

9. A.A. Tarasenko, P.V. Chepur, S.V. Chirkov, Neftyanoe khozyaystvo, Oil Industry, 10, 121-123 (2014)

10. A.A. Tarasenko, P.V. Chepur, S.V. Chirkov, Neftyanoe khozyaystvo, Oil Industry, 3, 123-125 (2016)

11. A.A. Tarasenko, P.V. Chepur, Y. Guan, Neftyanoe khozyaystvo, Oil Industry, 4, 134136 (2016)

12. P.V. Chepur, A.A. Tarasenko, Fundamental research, 7-1, 95-100 (2015)

13. P.V. Chepur, A.A. Tarasenko, Fundamental research, 12-1, 97-102 (2015)

14. P.V. Chepur, A.A. Tarasenko, A.A. Gruchenkova, Fundamental research, 12-3, 514519 (2014)

15. S.V. Chirkov, A.A. Tarasenko, P.V. Chepur, Oil and Gas, 5, $72-78$ (2014)

16. GOST $R$ 53166. Earthquakes. Influence of environmental conditions appearing in nature on the technical products (2009)

17. Design regulations NP 031-01. Design regulations for seismic resistant nuclear power plants / Approved by GGTN RF of 19. 10.2001 № 9.

18. Regulatory guide RTM 108.020.37-81. Equipment and piping of nuclear power plants. Seismic analysis (1981)

19. Design code SP 14.13330.2014, Seismic Building Design Code

20. A.A. Tarasenko, M.V. Sayapin, Oil and Gas, 1, 52-56 (1999)

21. A.A. Tarasenko, P.V. Chepur, Fundamental research, 12-1, 67-84 (2014)

22. P.V. Chepur, A.A. Tarasenko, Fundamental research, 2-8, 1671-1675 (2015) 